\title{
USE OF DIAZEPAM FOR TRANSPORTATION OF HIMALAYAN BLACK BEAR (SELENARCTOS THIBETINUS)
}

\author{
Nawab Nashiruddullah ${ }^{1}$ and Saidul Islam ${ }^{2}$
}

${ }^{1}$ Department of Pathology, ${ }^{2}$ Department of Parasitology, College of Veterinary Science, Assam Agricultural University, Khanapara, Guwahati, Assam 781022, India.

\begin{abstract}
A male wild Himalayan Black Bear (Selenarctos thibetinus) was chemically restrained with diazepam, dose rate of $2 \mathrm{mg} / \mathrm{kg}$ body weight intramuscularly in divided doses for translocation. Mild tranquillization was achieved without sedation. However, the animal showed moderate analgesia, muscle relaxation and listlessness. No side effects were exhibited. The animal could be translocated safely and it could fully recover after three hours of drug induction.
\end{abstract}

\section{Introduction}

Diazepam, a benzodiazepine compound has been used as a feed additive in domestic animals for its tranquillizing, antistress and growth stimulating effects. This group of drugs show dose related tranquilizing, sedative and hypnotic properties. This report discusses the various tranquilizing stages of diazepam in a young male wild Himalayan Black Bear (Selenarctos thibetinus) during its translocation.

\section{Materials and Methods}

A young male wild Himalayan Black Bear had to be tranquilized for translocation from the site of temporary rehabilitation and to its new destination site located $68 \mathrm{~km}$ away.

Diazepam (Calmpose inj.*) was selected as the drug of choice at a dose rate of $1 \mathrm{mg} / \mathrm{kg}$ body weight initially, with a total dose of $25 \mathrm{mg}$., intramuscularly. The animal calmed with no sedation and was boarded on a jeep inside a temporary wooden cage. The dimension of the cage was enough to allow the animal to move, the roof touching its back. The ambient temperature was $34^{\circ} \mathrm{C}$.

The animal initially responded with grunts on starting the vehicle. After about 10 minutes of journey, the animal became increasingly excited and hard to control, gnawing at the thinner planks. Diazepam $10 \mathrm{mg}$. was again injected intramuscularly. After 10 minutes, the journey was resumed. The bear got excited intermittently, thereafter with heavy panting due to heat, congestion and probably constant movement of the vehicle.

After 10 minutes of the administration of the second dose, the animal became increasingly restless and broke one side of the cage with frantic effort to come out. Diazepam $15 \mathrm{mg}$. was in-

Received 22 October 1998;

Accepted 6 December 1999 jected again intramuscularly to complete a dose regime of $2 \mathrm{mg} /$ $\mathrm{kg}$ body weight. After 15 minutes of administering the third dose the bear calmed down. The animal lay on its belly with relatively moderate muscle relaxation and analgesia but with complete listlessness. Transportation resumed soon after repairing the cage.

On arrival, the bear was allowed to creep out of the cage. The animal recovered fully an hour thereafter. Emesis or other complications were not exhibited.

\section{Results and Discussion}

Diazepam is described as a suitable drug for restraining wild animals (Fowler, 1978). The dosage varies from 1 to $3.5 \mathrm{mg} / \mathrm{kg}$ ( 0.5 to $2 \mathrm{mg} / \mathrm{lb})$, depending on the species and the degree of excitement at the time of injection. Onset of induction is reported to be within 1 to 2 minutes when given intravenously. If given intramuscularly, it takes effect within 15 to 30 minutes, depending on the dose. Diazepam is metabolized slowly. Clinical effects usually disappear within 60 to 90 minutes (Fowler, 1978).

In the present study, diazepam at the dose rate of $1 \mathrm{mg} / \mathrm{kg}$ body weight was not found to be sufficient, but responded well at the dose rate of $2 \mathrm{mg} / \mathrm{kg}$ body weight. However, a higher dose rate may be necessary for bigger and more agile and excited bears.

The present dose was found to be completely safe with no visible clinical side effects or toxicity. Similar findings have been reported when large doses of diazepam was given to dogs for prolonged periods (Hall \& Clarke, 1983).

\section{Acknowledgement}

NN acknowledges the kind help rendered by the D.F.O., Western Assam Wildlife Division, Mangaldai, Assam, India. He is also grateful to all his well-wishers for their help and advice during clinical monitoring and health recovery of the bear at its temporary rehabilitation site.

\section{References}

Fowler, M.E. (1978). Zoo and Wild Animal Medicine. W.B.Saunders Co., Philadelphia.

Hall, L.W. and K.W. Clarke (1983). Veterinary Anaesthesia. 8th edition. ELBS and Bailliere \& Tindall, London.

* Diazepam 10mg, per 2ml, Ranbaxy India, Bombay 